\title{
Comparison of Fondaparinux and Enoxaparin in Acute Coronary Syndromes
}

\author{
The Fifth Organization to Assess Strategies \\ in Acute Ischemic Syndromes Investigators*:
}

ABSTRACT

The Writing Committee (Salim Yusuf, D.Phil., M.B., B.S., Shamir R. Mehta, M.D. Susan Chrolavicius, B.A., Rizwan Afzal, M.Sc., Janice Pogue, M.Sc., Christopher B. Granger, M.D., Andrzej Budaj, Ph.D., Ron J.G. Peters, M.D., Jean-Pierre Bassand, M.D. Lars Wallentin, Ph.D., Campbell Joyner, M.D., and Keith A.A. Fox, F.R.C.P.) assumes responsibility for the overall content and integrity of the article. Address reprint requests to Dr. Yusuf at the Population Health Research Institute, McMaster Clinic, Ham ilton General Hospital, 237 Barton St. East, Hamilton, ON L8L 2X2, Canada.

*The Fifth Organization to Assess Strategies in Acute Ischemic Syndromes (OASIS-5) investigators and committees are listed in the Appendix.

This article was published at www.nejm.org on March 14, 2006.

N Engl J Med 2006;354:1464-76. Copyright $\odot 2006$ Massachusetts Medical Society.

\section{BACKGROUND}

The combined use of anticoagulants, antiplatelet agents, and invasive coronary procedures reduces ischemic coronary events but also increases bleeding in patients with acute coronary syndromes. We therefore assessed whether fondaparinux would preserve the anti-ischemic benefits of enoxaparin while reducing bleeding.

\section{METHODS}

We randomly assigned 20,078 patients with acute coronary syndromes to receive either fondaparinux ( $2.5 \mathrm{mg}$ daily) or enoxaparin (1 mg per kilogram of body weight twice daily) for a mean of six days and evaluated death, myocardial infarction, or refractory ischemia at nine days (the primary outcome); major bleeding; and their combination. Patients were followed for up to six months.

\section{RESULTS}

The number of patients with primary-outcome events was similar in the two groups ( 579 with fondaparinux [5.8 percent] vs. 573 with enoxaparin [5.7 percent]; hazard ratio in the fondaparinux group, 1.01; 95 percent confidence interval, 0.90 to 1.13), satisfying the noninferiority criteria. The number of events meeting this combined outcome showed a nonsignificant trend toward a lower value in the fondaparinux group at 30 days ( 805 vs. $864, \mathrm{P}=0.13$ ) and at the end of the study (1222 vs. 1308 , $\mathrm{P}=0.06$ ). The rate of major bleeding at nine days was markedly lower with fondaparinux than with enoxaparin (217 events [2.2 percent] vs. 412 events [4.1 percent]; hazard ratio, $0.52 ; \mathrm{P}<0.001)$. The composite of the primary outcome and major bleeding at nine days favored fondaparinux (737 events [7.3 percent] vs. 905 events [9.0 percent]; hazard ratio, 0.81; $\mathrm{P}<0.001$ ). Fondaparinux was associated with a significantly reduced number of deaths at 30 days ( 295 vs. $352, \mathrm{P}=0.02)$ and at 180 days (574 vs. $638, \mathrm{P}=0.05$ ).

\section{CONCLUSIONS}

Fondaparinux is similar to enoxaparin in reducing the risk of ischemic events at nine days, but it substantially reduces major bleeding and improves long term mortality and morbidity. (ClinicalTrials.gov number, NCT00139815.) 
T HE COMBINED USE OF ANTICOAGUlants, ${ }^{1}$ antiplatelet agents, ${ }^{2-4}$ and an invasive strategy ${ }^{5}$ in high-risk patients with acute coronary syndromes reduces ischemic coronary events but also increases bleeding. Bleeding may increase the risk of death, ${ }^{6}$ myocardial infarction, and stroke. Therefore, future therapies should either preserve or enhance benefits without increasing bleeding. Unfractionated heparin and lowmolecular-weight heparins are commonly used in patients with acute coronary syndromes, but enoxaparin may be modestly superior to unfractionated heparin in reducing the risk of death or myocardial infarction. ${ }^{7}$

Fondaparinux (Arixtra, GlaxoSmithKline), a synthetic pentasaccharide, selectively binds antithrombin and causes rapid and predictable inhibition of factor $\mathrm{Xa}^{8}{ }^{8}$ Fondaparinux is more effective than enoxaparin in preventing venous thrombosis in patients undergoing orthopedic surgery ${ }^{9}$ and is similar in effectiveness to enoxaparin or unfractionated heparin in patients with deep-vein thrombosis or pulmonary embolism. ${ }^{10,11}$ Pilot trials involving patients with acute coronary syndromes ${ }^{12,13}$ and those undergoing percutaneous coronary intervention ${ }^{14}$ suggest that fondaparinux may be as effective as enoxaparin or safer than unfractionated heparin. The Fifth Organization to Assess Strategies in Acute Ischemic Syndromes (OASIS-5) trial compared the efficacy and safety of fondaparinux and enoxaparin (Lovenox, Sanofi-Aventis) in high-risk patients with unstable angina or myocardial infarction without ST-segment elevation.

METHODS

\section{STUDY DESIGN}

OASIS-5 was a randomized, double-blind, doubledummy trial in which fondaparinux was compared with enoxaparin in patients with unstable angina or myocardial infarction without ST-segment elevation; 20,078 patients from 576 centers in 41 countries were included. Details of the protocol are reported elsewhere. ${ }^{15}$ The study was conducted independently by the steering committee and the Population Health Research Institute, McMaster University and Hamilton Health Sciences, Hamilton, Ontario, Canada. The study was designed by the steering committee, and the data were coordinated and managed independently by the Population Health Research Institute, McMas- ter University and Hamilton Health Sciences. The first five members of the writing committee vouch for the accuracy and completeness of the data and analysis. The study protocol was approved by the respective ethics committees and regulatory bodies. The principal investigator had full access to the data and drafted the manuscript with input from the entire writing committee.

\section{STUDY PATIENTS}

Patients were randomly assigned to a study group within 24 hours after the onset of symptoms and were eligible if they met at least two of the three following criteria: an age of at least 60 years, an elevated level of troponin or creatine kinase $\mathrm{MB}$ isoenzyme, or electrocardiographic changes indicative of ischemia. Patients with contraindications to low-molecular-weight heparin, recent hemorrhagic stroke, indications for anticoagulation other than an acute coronary syndrome, or a serum creatinine level of at least $3 \mathrm{mg}$ per deciliter (265 $\mu \mathrm{mol}$ per liter) were excluded.

\section{OUTCOMES}

The objective with respect to the primary efficacy outcome (death, myocardial infarction, or refractory ischemia) was to demonstrate the noninferiority of fondaparinux as compared with enoxaparin at nine days. The primary safety objective was to determine whether fondaparinux was superior to enoxaparin in preventing major bleeding.

Patients were followed for a minimum of 90 days and a maximum of 180 days. Prespecified secondary outcomes included the following: death or myocardial infarction; death, myocardial infarction, or refractory ischemia; and the individual components of these composite outcomes at 30 days and at the end of the study. Information on strokes was also systematically collected. The primary safety outcome was major bleeding at nine days. The balance of benefit and risk was assessed on the basis of the combination of the primary efficacy and safety outcomes. All events were adjudicated in a blinded fashion by a committee. Definitions of events have been described separately ${ }^{15}$ and are given in part 1 of the Supplementary Appendix (available with the full text of this article at www.nejm.org).

\section{STUDY-DRUG ADMINISTRATION}

After providing written informed consent, patients were randomly assigned, by means of a central 


\begin{tabular}{|c|c|c|}
\hline Characteristic & $\begin{array}{l}\text { Enoxaparin } \\
(\mathrm{N}=10,021)\end{array}$ & $\begin{array}{c}\text { Fondaparinux } \\
(\mathrm{N}=10,057)\end{array}$ \\
\hline Age $-y r$ & $66.6 \pm 11.0$ & $66.6 \pm 10.8$ \\
\hline Male sex - no. (\%) & $6148(61.4)$ & $6231(62.0)$ \\
\hline Time from onset of pain to randomization - $\mathrm{hr}$ & $12.7 \pm 6.8$ & $12.7 \pm 6.8$ \\
\hline Heart rate - beats/min & $73.0 \pm 13.5$ & $73.0 \pm 13.5$ \\
\hline Systolic blood pressure $-\mathrm{mm} \mathrm{Hg}$ & $136.3 \pm 22.1$ & $136.6 \pm 22.7$ \\
\hline \multicolumn{3}{|l|}{ Diagnosis at study entry — no. (\%) } \\
\hline Unstable angina & $4517(45.1)$ & $4581(45.6)$ \\
\hline Suspected myocardial infarction & $5502(54.9)$ & $5474(54.4)$ \\
\hline \multicolumn{3}{|l|}{ Medical history — no. (\%) } \\
\hline Myocardial infarction & $2580(25.7)$ & $2584(25.7)$ \\
\hline $\mathrm{CABG}$ or $\mathrm{PCl}$ & $1953(19.5)$ & $2022(20.1)$ \\
\hline Stroke & $647(6.5)$ & $597(5.9)$ \\
\hline Heart failure & $1386(13.8)$ & $1402(13.9)$ \\
\hline Hypertension & $6721(67.1)$ & $6777(67.4)$ \\
\hline Diabetes & $2503(25.0)$ & $2575(25.6)$ \\
\hline Current or former smoker & $5473(54.6)$ & $5440(54.1)$ \\
\hline Any electrocardiographic abnormality — no. (\%) & 7993 (79.8) & $8109(80.6)$ \\
\hline ST-segment depression $\geq 1 \mathrm{~mm}-$ no. (\%) & $5045(50.3)$ & $5197(51.7)$ \\
\hline
\end{tabular}

telephone system, to receive either fondaparinux at a dose of $2.5 \mathrm{mg}$ once daily plus placebo enoxaparin twice daily by subcutaneous injection or enoxaparin at a dose of $1 \mathrm{mg}$ per kilogram of body weight twice daily plus placebo fondaparinux once daily by subcutaneous injection. In patients whose creatinine clearance was below $30 \mathrm{ml}$ per minute, the enoxaparin dosage was reduced to $1 \mathrm{mg}$ per kilogram once daily. Fondaparinux could be given until hospital discharge or for up to eight days (whichever occurred first), and enoxaparin was to be given for two to eight days or until the patient was in clinically stable condition, in an approach consistent with the current approval for its use in persons with unstable angina and myocardial infarction without ST-segment elevation. Patients received other standard treatments at the investigators' discretion.

Cardiac catheterization could be performed at any time. If percutaneous coronary intervention was to be considered, we recommended use of clopidogrel and aspirin at least six hours before the procedure. The double-blind arrangement was maintained during percutaneous coronary intervention. Patients in the enoxaparin group received no additional anticoagulant if they had received their subcutaneous enoxaparin injection six hours or less before percutaneous coronary intervention; if the interval was greater than six hours, the dose of weight-adjusted unfractionated heparin was $0.013 \mathrm{ml}$ per kilogram intravenously if a glycoprotein IIb/IIIa antagonist was used and was $0.02 \mathrm{ml}$ per kilogram intravenously if no glycoprotein IIb/IIIa antagonist was used. Within six hours of the last subcutaneous dose of fondaparinux, patients undergoing percutaneous coronary intervention in the absence of a glycoprotein IIb/IIIa antagonist received an additional $2.5 \mathrm{mg}$ of intravenous fondaparinux; within six hours after the last subcutaneous dose of fondaparinux, $2.5 \mathrm{mg}$ of intravenous fondaparinux (with a glycoprotein IIb/IIIa antagonist) or $5.0 \mathrm{mg}$ of intravenous fondaparinux (without a glycoprotein IIb/IIIa antagonist) was administered (part 2 of the Supplementary Appendix).

\section{STATISTICAL ANALYSIS}

A sample size of 16,000 was planned on the basis of an expected primary-event rate of 8 percent at nine days, assuming a one-sided alpha level of 2.5 percent and a noninferiority margin (delta) of 1.185 . This noninferiority margin was derived 


\begin{tabular}{|c|c|c|}
\hline Characteristic & $\begin{array}{l}\text { Enoxaparin } \\
(\mathrm{N}=10,021)\end{array}$ & $\begin{array}{l}\text { Fondaparinux } \\
(\mathrm{N}=10,057)\end{array}$ \\
\hline \multicolumn{3}{|c|}{ Medications at the time of randomization — no. (\%) } \\
\hline Aspirin & $7829(78.1)$ & $7815(77.7)$ \\
\hline Clopidogrel or ticlopidine & $3160(31.5)$ & $3134(31.2)$ \\
\hline Unfractionated heparin & $1787(17.8)$ & $1779(17.7)$ \\
\hline Low-molecular-weight heparin & $3192(31.9)$ & $3138(31.2)$ \\
\hline ACE inhibitor or ARB & $5131(51.2)$ & $5135(51.1)$ \\
\hline Beta-blocker & $6033(60.2)$ & $5954(59.2)$ \\
\hline Calcium-channel blocker & $2246(22.4)$ & $2274(22.6)$ \\
\hline Lipid-lowering agent & $3862(38.5)$ & $3843(38.2)$ \\
\hline \multicolumn{3}{|c|}{ Medications in the hospital after randomization — no. (\%) } \\
\hline Aspirin & $9767(97.5)$ & 9809 (97.5) \\
\hline Clopidogrel or ticlopidine & $6735(67.2)$ & $6797(67.6)$ \\
\hline Unfractionated heparin & $3131(31.2)$ & $2211(22.0)$ \\
\hline ACE inhibitor or ARB & $7630(76.1)$ & 7535 (74.9) \\
\hline Beta-blocker & $8792(87.7)$ & $8766(87.2)$ \\
\hline Lipid-lowering agent & $7856(78.4)$ & $7988(79.4)$ \\
\hline \multicolumn{3}{|l|}{ Procedures in the hospital — no. (\%) } \\
\hline Coronary angiography & $6325(63.1)$ & $6390(63.5)$ \\
\hline $\mathrm{PCl}$ & $3435(34.3)$ & $3454(34.3)$ \\
\hline CABG & $897(9.0)$ & $965(9.6)$ \\
\hline \multicolumn{3}{|l|}{ Procedures after discharge — no. (\%) } \\
\hline Coronary angiography & $839(8.4)$ & $819(8.1)$ \\
\hline $\mathrm{PCl}$ & $527(5.3)$ & $516(5.1)$ \\
\hline CABG & $560(5.6)$ & 569 (5.7) \\
\hline
\end{tabular}

* Plus-minus values are means \pm SD. CABG denotes coronary-artery bypass grafting, $\mathrm{PCl}$ percutaneous coronary intervention, $A C E$ angiotensin-converting enzyme, and $A R B$ angiotensin-receptor blocker.

from a meta-analysis of studies that demonstrated the benefit of adding unfractionated heparin or low-molecular-weight heparin as short-term treatment in patients treated with aspirin. ${ }^{1}$ It showed that unfractionated heparin or low-molecular-weight heparin halves the risk of myocardial infarction or death (odds ratio, 0.53 ; 95 percent confidence interval, 0.38 to 0.73 ) as compared with placebo or no treatment during the first week of therapy. (The effect of low-molecular-weight heparin on refractory ischemia, when evaluated, was similar to its effect on myocardial infarction.) When the inverse of the above result is taken, the excess risk due to placebo or no treatment as compared with unfractionated heparin or low-molecular-weight heparin is 1.89 ( 95 percent confidence interval, 1.37 to 2.63 ). The noninferiority margin of 1.185 was chosen in order to avoid a loss of greater than half the lower bound of the 95 percent confidence interval (1.37). ${ }^{16} \mathrm{~A}$ blinded review of the overall event rate in the first 4000 patients indicated that the event rate was lower than expected. Therefore, the inclusion criteria were modified so that persons under the age of 60 years were required to have both an elevation of biomarkers and ischemic electrocardiographic changes, and the sample size was increased to 20,000 patients.

The analyses include all patients who underwent randomization. The hazard ratio (for fondaparinux vs. enoxaparin) and two-sided 95 percent confidence interval were calculated with use of a Cox proportional-hazards model, with the treatment group as the only covariate. Rates presented 
are Kaplan-Meier rates (e.g., the rate of major bleeding).

The independent data and safety monitoring board monitored outcomes. During the trial, a few cases of coronary and catheter-related thrombosis were reported during percutaneous coronary intervention. These reports led to concern at some sites and on the part of some regulatory bodies, and the concern was conveyed to the data and safety monitoring board; after repeated review, the members of the board recommended continuation of the study. However, the operations committee (whose members were unaware of patients' treatment assignments) recommended steps to ensure that the study medications were appropriately administered intravenously before the procedure and allowed centers to use 200 IU of unfractionated heparin to flush the catheters.

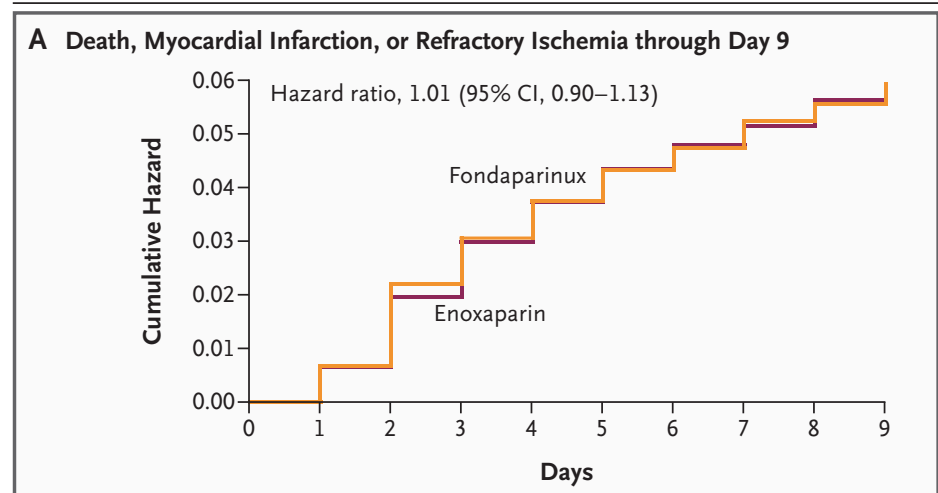

No. at Risk Enoxaparin Fondaparinux

$\begin{array}{lllllllll}10,021 & 9954 & 9824 & 9724 & 9652 & 9593 & 9550 & 9515 & 9470\end{array}$

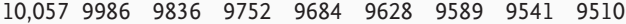

B Major Bleeding through Day 9

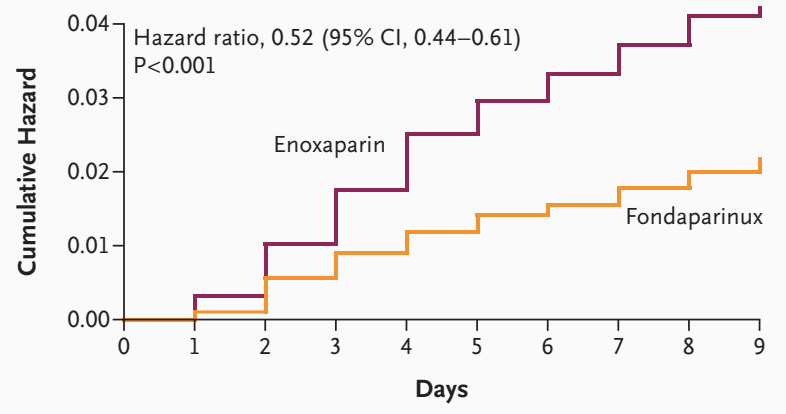

No. at Risk

Enoxaparin

Fondaparinux

$\begin{array}{lllllllll}10,021 & 9,979 & 9871 & 9774 & 9682 & 9625 & 9575 & 9527 & 9478\end{array}$

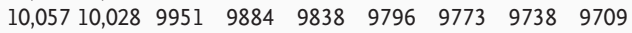

Figure 1. Cumulative Risks of Death, Myocardial Infarction, or Refractory Ischemia (Panel A) and of Major Bleeding (Panel B) through Day 9.

The hazard ratios are for the fondaparinux group as compared with the enoxaparin group. $\mathrm{Cl}$ denotes confidence interval.
All reported events not refuted by the adjudication committee were included. Vital status was ascertained for 20,066 of the 20,078 randomly assigned patients (99.9 percent); 7 patients in the fondaparinux group and 5 in the enoxaparin group were lost to follow-up by day 9 .

\section{RESULTS}

The characteristics of the patients and their ancillary therapies are listed in Table 1 . Seventy percent of the patients were enrolled by hospitals with a cardiac-catheterization laboratory.

\section{EFFICACY}

The primary efficacy outcome (death, myocardial infarction, or refractory ischemia at nine days) occurred in 579 of the 10,057 patients randomly assigned to receive fondaparinux (5.8 percent), as compared with 573 of the 10,021 patients assigned to receive enoxaparin (5.7 percent) (hazard ratio, 1.01; 95 percent confidence interval, 0.90 to 1.13 ) (Fig. $1 \mathrm{~A}$ and Table 2). This result confirms the noninferiority of fondaparinux as compared with enoxaparin because the upper confidence limit is well below the prespecified boundary of 1.185 ( $\mathrm{P}=0.007$ for noninferiority). The rates of the main secondary outcome (death or myocardial infarction) were also similar, at 4.1 percent in the fondaparinux group and 4.1 percent in the enoxaparin group (hazard ratio, 0.99 ; 95 percent confidence interval, 0.86 to 1.13 ); again, the upper confidence limit is below the noninferiority boundary $(\mathrm{P}=0.005)$.

At 30 days, there was a trend toward a lower rate of death, myocardial infarction, or refractory ischemia with fondaparinux than with enoxaparin (8.0 percent vs. 8.6 percent; hazard ratio, 0.93 ; 95 percent confidence interval, 0.84 to 1.02 ) and of the composite of death or myocardial infarction (6.2 percent vs. 6.8 percent; hazard ratio, 0.90 ; 95 percent confidence interval, 0.81 to 1.01 ) (Table 2). These differences were due to a significant reduction in mortality with fondaparinux (2.9 percent, vs. 3.5 percent with enoxaparin; hazard ratio, 0.83; 95 percent confidence interval, 0.71 to $0.97 ; \mathrm{P}=0.02$ ). The above differences persisted until the end of follow-up: the rates of death, myocardial infarction, or refractory ischemia were 12.3 percent in the fondaparinux group and 13.2 percent in the enoxaparin group (hazard ratio, 0.93; 95 percent confidence interval, 
0.86 to $1.00 ; \mathrm{P}=0.06$ ); the rates of death or myocardial infarction were 10.5 percent and 11.4 percent, respectively (hazard ratio, 0.92; 95 percent confidence interval, 0.84 to $1.00 ; \mathrm{P}=0.05$ ); and the rates of death were 5.8 percent and 6.5 percent, respectively (hazard ratio, 0.89; 95 percent confidence interval, 0.80 to $1.00 ; \mathrm{P}=0.05$ ) (Fig.
2 and Table 2, and Fig. 1 of the Supplementary Appendix).

\section{BLEEDING}

The rate of major bleeding at nine days was substantially lower in the fondaparinux group than in the enoxaparin group (2.2 percent vs. 4.1 per-

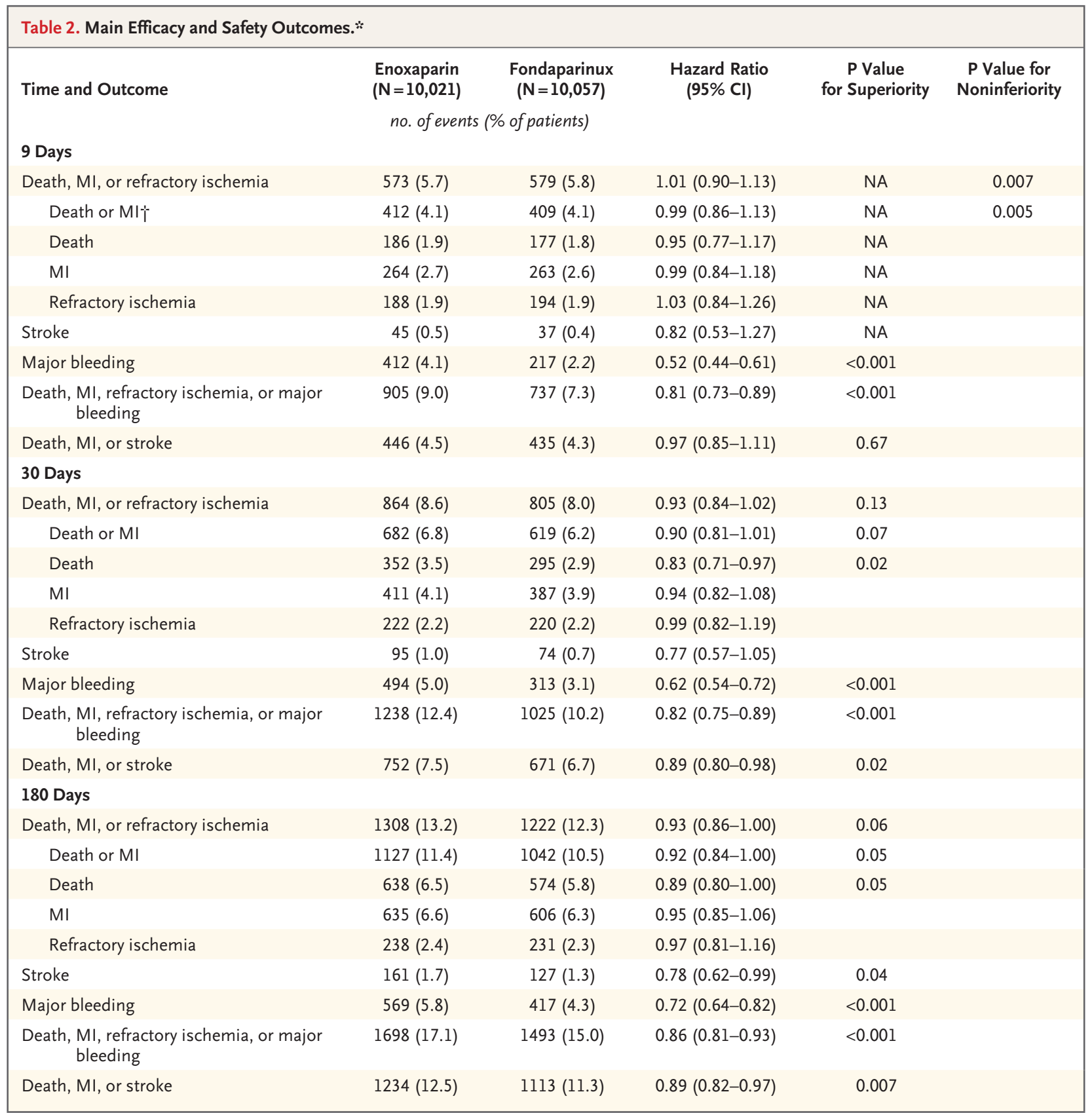

* Strokes were prospectively documented and centrally adjudicated. The composite of death, myocardial infarction (MI), or stroke was not a prespecified outcome. $\mathrm{Cl}$ denotes confidence interval, and NA not applicable.

$\uparrow$ The noninferiority criterion was based on the primary outcome, but the secondary outcome of death or MI also satisfied this criterion. 
cent; hazard ratio, 0.52; 95 percent confidence interval, 0.44 to $0.61 ; \mathrm{P}<0.001$ ) (Fig. $1 \mathrm{~B}$ and $\mathrm{Ta}$ ble 2). This difference persisted during long-term follow-up. Fondaparinux was associated with a significant reduction in the number of patients with fatal bleeding (7, vs. 22 in the enoxaparin group; $\mathrm{P}=0.005$ ) and severe bleeding according to the Thrombolysis in Myocardial Infarction criteria ${ }^{17}$ (70, vs. 126; hazard ratio, 0.55; 95 percent confidence interval, 0.41 to $0.74 ; \mathrm{P}<0.001)$. Larger differences in the rates of minor bleeding were observed (1.1 percent in the fondaparinux group vs. 3.2 percent in the enoxaparin group), so that the rates of total bleeding were substantially lower with fondaparinux than with enoxaparin (3.3 percent vs. 7.3 percent; hazard ratio, 0.44; 95 per-

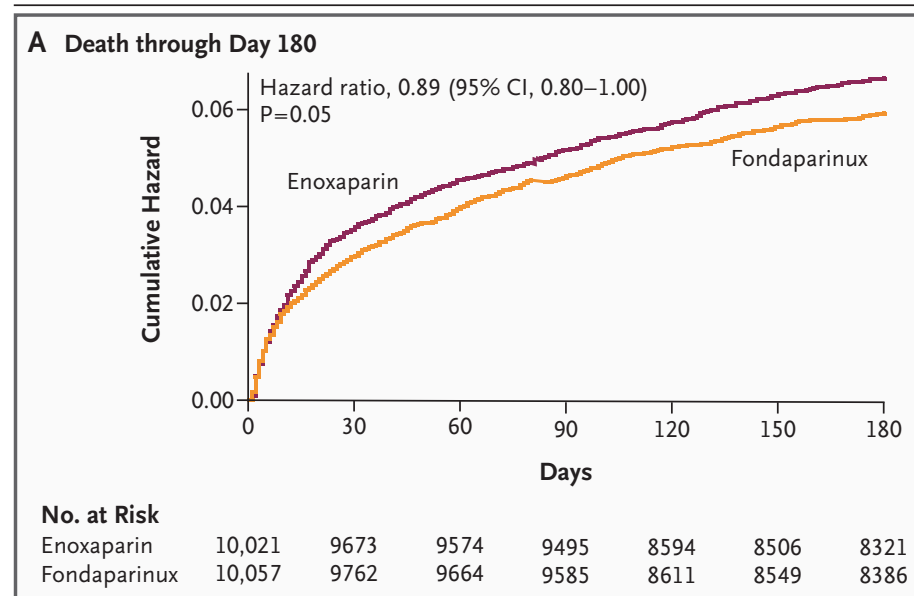

B Death, Myocardial Infarction, or Stroke through Day 180

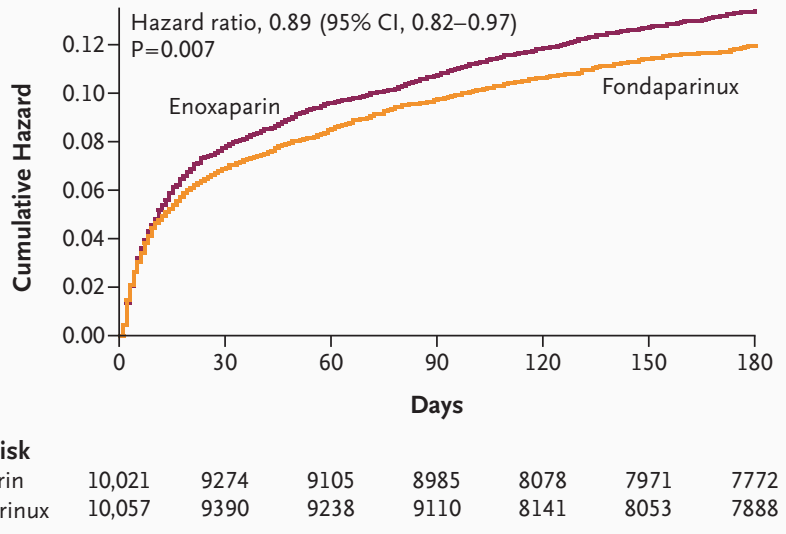

Figure 2. Cumulative Risks of Death (Panel A) and of Death, Myocardial Infarction, or Stroke (Panel B) through Day 180.

The hazard ratios are for the fondaparinux group as compared with the enoxaparin group. $\mathrm{Cl}$ denotes confidence interval. cent confidence interval, 0.39 to 0.50 ). Although the number of patients with intracranial bleeding was the same $-7-$ in each group, the numbers of patients with major bleeding requiring surgical intervention (41 vs. 77), retroperitoneal bleeding (9 vs. 37), transfusions (164 vs. 287), and bleeding associated with death at the end of the study (38 vs. 79) were significantly lower with fondaparinux than with enoxaparin $(\mathrm{P}<0.001$ for all comparisons). The rate of major bleeding was significantly lower with fondaparinux than with enoxaparin among patients with a creatinine clearance below $30 \mathrm{ml}$ per minute $(6$ of $265 \mathrm{pa}-$ tients [2.4 percent] had major bleeding vs. 26 of 270 [9.9 percent], $\mathrm{P}=0.001$ ) or a creatinine clearance of at least $30 \mathrm{ml}$ per minute (211 of 9743 [2.2 percent] vs. 384 of 9699 [4.0 percent], $\mathrm{P}<0.001$ ).

Regardless of treatment, patients who had major bleeding during hospitalization had significantly higher rates of death (13.2 percent vs. 2.8 percent), reinfarction (11.9 percent vs. 3.6 percent), or stroke (3.5 percent vs. 0.7 percent) at 30 days $(\mathrm{P}<0.001)$ and at 180 days (data not shown) than patients without major or minor bleeding. The mortality rate among those who had minor bleeding was also higher at 30 days than among those with no bleeding episodes (6.9 percent vs. 2.8 percent). These higher event rates associated with bleeding persisted after adjustment for various clinical characteristics associated with bleeding. In analyzing the difference of 64 between the groups in the number of deaths at the end of the study, we found that 41 fewer patients in the fondaparinux group than in the enoxaparin group died after major bleeding (38 vs. 79) and that 20 fewer patients in the fondaparinux group died after minor bleeding (13 vs. 33). Therefore, almost the entire difference in mortality between the groups at the end of the study could be attributed to the lower rate of bleeding with fondaparinux.

\section{BALANCE OF BENEFIT AND RISK}

The composite of death, myocardial infarction, refractory ischemia, or major bleeding occurred in 7.3 percent of the patients in the fondaparinux group, as compared with 9.0 percent of the patients in the enoxaparin group (hazard ratio, 0.81 ; 95 percent confidence interval, 0.73 to 0.89 ; $\mathrm{P}<0.001$ ) at nine days (Table 2, and Fig. 2 and 3 of the Supplementary Appendix). This difference persisted until the end of the study. 


\section{OTHER EFFICACY OUTCOMES}

There was a significant reduction in the rate of stroke with fondaparinux (1.3 percent, vs. 1.7 percent with enoxaparin; $\mathrm{P}=0.04)$ at the end of the study. The composite outcome of death, myocardial infarction, or stroke was also significantly reduced with fondaparinux (11.3 percent vs. 12.5 percent; hazard ratio, 0.89; 95 percent confidence interval, 0.82 to $0.97 ; \mathrm{P}=0.007$ ) (Table 2 and Fig. 2).

\section{SUBGROUP ANALYSES}

The benefits and risks were consistent among most subgroups. Consequently, the reduction in the composite outcome of death, myocardial infarction, refractory ischemia, or major bleeding with fondaparinux as compared with enoxaparin was observed in all the subgroups. The rates of bleeding were consistently lower with fondaparinux, regardless of whether unfractionated heparin was administered before randomization (2.0 percent in the fondaparinux group vs. 4.0 percent in the enoxaparin group among those who did not receive unfractionated heparin $[\mathrm{P}<0.001]$ and 3.0 percent vs. 5.0 percent among those who did receive unfractionated heparin $[\mathrm{P}=0.003]$ ) (Fig. 3) or after randomization. The rates of bleeding were also lower with fondaparinux regardless of the baseline creatinine level and regardless of the presence or absence of a catheterization laboratory at the center.

\section{REVASCULARIZATION PROCEDURES}

The proportions of patients undergoing percutaneous coronary intervention (39.5 percent in the fondaparinux group and 39.5 percent in the enoxaparin group) or coronary-artery bypass grafting (15.3 percent and 14.5 percent, respectively) were similar in the two groups. Among patients undergoing percutaneous coronary intervention in the hospital, the rates of the combination of death, myocardial infarction, and refractory ischemia were similar at 9 days $(9.3$ percent in the fondaparinux group and 8.6 percent in the enoxaparin group), at 30 days (10.4 percent and 9.6 percent, respectively), and at the end of the study (12.9 percent and 12.3 percent, respectively). At 30 days, the rates of death (2.0 percent with fondaparinux and 2.1 percent with enoxaparin) (Table 3) and of death or myocardial infarction (7.1 percent and 6.8 percent) were similar in the two groups. The rates of coronary complications during the procedure also were similar. The rates of clinical out- comes and procedural complications were similar in the two groups both before and after the amendment recommended by the operations committee.

The rate of major bleeding 48 hours after the procedure was significantly lower with fondaparinux than with enoxaparin (1.6 percent vs. 3.6 percent before the amendment and 1.4 percent vs. 3.4 percent after the amendment; $\mathrm{P}<0.001$ for both comparisons). Bleeding was significantly reduced with fondaparinux among patients receiving additional heparin $(\mathrm{P}<0.001)$ and those not receiving it $(\mathrm{P}<0.001)$. There was an increase in the rate of guiding-catheter thrombus formation with fondaparinux (29 episodes $[0.9$ percent], vs. 8 episodes with enoxaparin [0.3 percent]) - a difference that was observed both before (1.2 percent vs. 0.3 percent) and after ( 0.7 percent vs. 0.2 percent) the amendment. The rates of other complications of percutaneous coronary intervention were significantly lower with fondaparinux than with enoxaparin (pseudoaneurysms requiring closure, 1.0 percent vs. 1.6 percent $[P=0.04]$; large hematoma, 1.6 percent vs. 4.4 percent $[\mathrm{P}<0.001]$; and complications involving the vascular access site, 3.3 percent vs. 8.1 percent $[\mathrm{P}<0.001])$. The rate of death, myocardial infarction, stroke, major bleeding, or any procedural complication at nine days was $\mathbf{1 6 . 6}$ percent with fondaparinux, as compared with 20.6 percent with enoxaparin (relative risk, 0.81 ; 95 percent confidence interval, 0.73 to 0.90 ; $\mathrm{P}<0.001)$ (Table 3).

\section{ADHERENCE}

At least one dose of allocated study drug was administered to 99.2 percent of the patients in the fondaparinux group and 99.4 percent of those in the enoxaparin group. The mean durations of treatment were similar in the two groups (5.4 and 5.2 days, respectively).

\section{DISCUSSION}

Our study has three important findings. First, in the short term, fondaparinux and enoxaparin have similar efficacy. Second, as compared with enoxaparin, fondaparinux substantially reduces bleeding. Third, the reduced bleeding that accompanies the use of fondaparinux is associated with lower long-term mortality and morbidity.

Fondaparinux was statistically noninferior to 


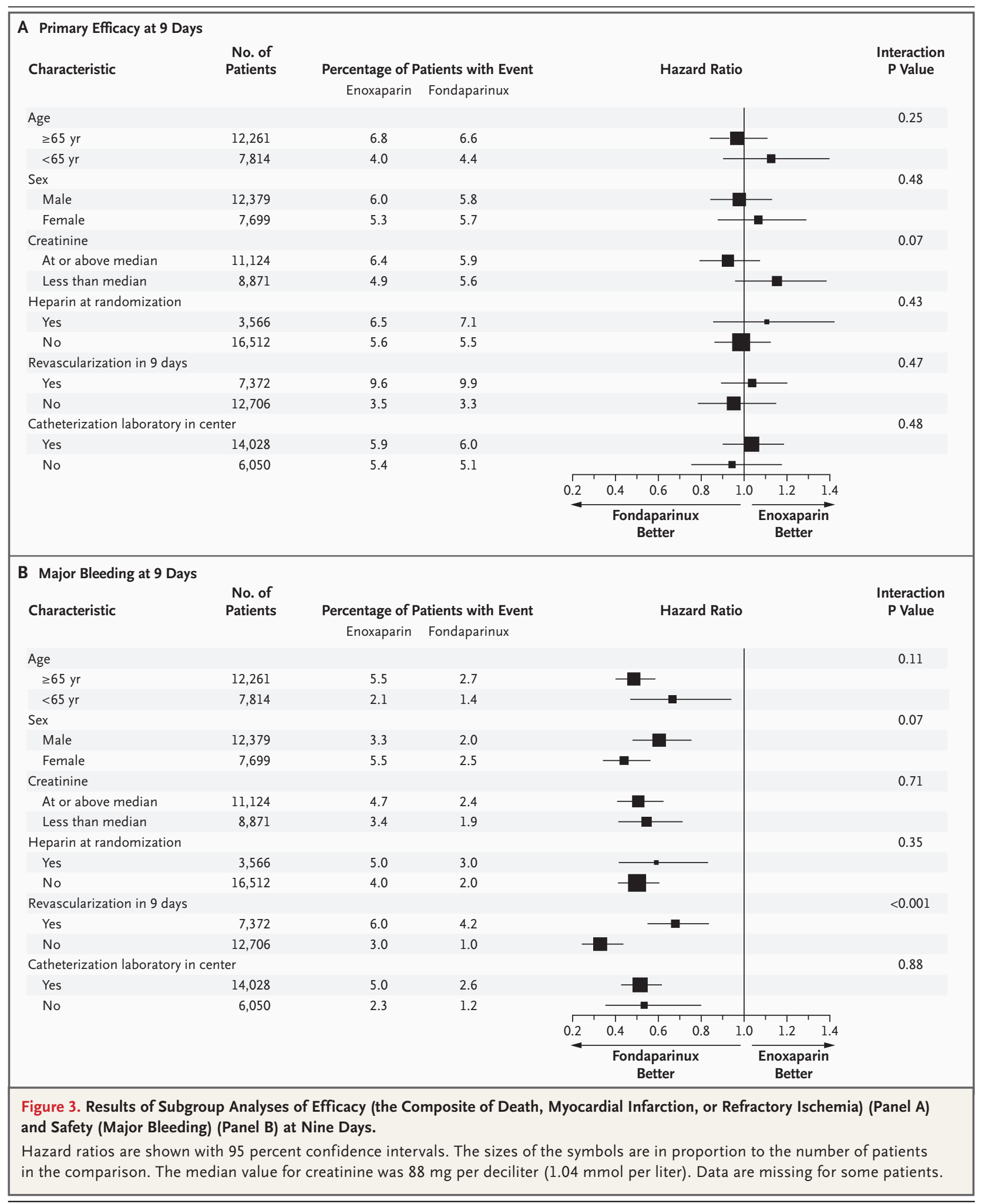




\begin{tabular}{|c|c|c|c|c|}
\hline Variable & $\begin{array}{l}\text { Enoxaparin } \\
(\mathrm{N}=3104)\end{array}$ & $\begin{array}{l}\text { Fondaparinux } \\
(\mathrm{N}=3135)\end{array}$ & $\begin{array}{l}\text { Relative Risk } \\
\text { (95\% CI) }\end{array}$ & P Value \\
\hline & \multicolumn{2}{|c|}{ no. of events (\% of patients) } & & \\
\hline \multicolumn{5}{|l|}{ Concomitant antithrombotic drugs } \\
\hline Unfractionated heparin & $1724(55.5)$ & $651(20.8)$ & & \\
\hline Glycoprotein IIb/IIla inhibitor & $1273(41.0)$ & $1308(41.7)$ & & \\
\hline Thienopyridines & $2317(74.6)$ & $2348(74.9)$ & & \\
\hline \multicolumn{5}{|l|}{ Complications involving the vascular access site } \\
\hline Any complication & $251(8.1)$ & $103(3.3)$ & $0.41(0.33-0.51)$ & $<0.001$ \\
\hline Pseudoaneurysm & $49(1.6)$ & $31(1.0)$ & $0.63(0.40-0.98)$ & \\
\hline Large hematoma & $138(4.4)$ & $50(1.6)$ & $0.36(0.26-0.49)$ & \\
\hline \multicolumn{5}{|l|}{$\mathrm{PCl}$-related coronary complication $\nmid$} \\
\hline Any complication & $268(8.6)$ & $299(9.5)$ & $1.11(0.94-1.29)$ & 0.21 \\
\hline $\begin{array}{l}\text { Abrupt closure, new thrombus with reduced } \\
\text { flow, dissection, or no reflow }\end{array}$ & $161(5.2)$ & $188(6.0)$ & $1.16(0.94-1.42)$ & \\
\hline $\begin{array}{l}\text { Catheter-related thrombus not resulting in } \\
\text { clinical complications }\end{array}$ & $3(0.1)$ & $9(0.3)$ & $2.99(0.81-11.04)$ & 0.08 \\
\hline \multirow[t]{2}{*}{ All catheter-related thrombit } & $8(0.4)$ & $29(0.9)$ & $3.59(1.64-7.84)$ & 0.001 \\
\hline & & \multicolumn{3}{|c|}{ Hazard Ratio $(95 \% \mathrm{Cl})$} \\
\hline \multicolumn{5}{|l|}{ Clinical events at 9 days } \\
\hline Death & $38(1.2)$ & $37(1.2)$ & $0.96(0.62-1.51)$ & \\
\hline MI & $154(5.0)$ & $161(5.1)$ & $1.04(0.84-1.28)$ & \\
\hline Stroke & $13(0.4)$ & $13(0.4)$ & $0.99(0.46-2.13)$ & \\
\hline Major bleeding & $158(5.1)$ & $72(2.3)$ & $0.45(0.34-0.59)$ & \\
\hline Death, MI, or stroke & $190(6.1)$ & $198(6.3)$ & $1.03(0.87-1.25)$ & \\
\hline Death, MI, stroke, or major bleeding & $321(10.3)$ & $255(8.2)$ & $0.79(0.67-0.92)$ & 0.003 \\
\hline $\begin{array}{l}\text { Any procedural complication, major bleeding, } \\
\text { death, MI, or stroke at } 9 \text { days }\end{array}$ & $638(20.6)$ & $521(16.6)$ & $0.81(0.73-0.90)$ & $<0.001$ \\
\hline \multicolumn{5}{|l|}{ Clinical events at 30 days } \\
\hline Death & $65(2.1)$ & $62(2.0)$ & $0.94(0.67-1.33)$ & \\
\hline MI & $169(5.4)$ & $179(5.7)$ & $1.05(0.86-1.29)$ & \\
\hline Stroke & $22(0.7)$ & $18(0.6)$ & $0.81(0.44-1.51)$ & \\
\hline Major bleeding & $169(5.4)$ & $87(2.8)$ & $0.51(0.40-0.66)$ & \\
\hline Death, MI, or stroke & $228(7.3)$ & $231(7.4)$ & $1.00(0.84-1.20)$ & \\
\hline Death, MI, stroke, or major bleeding & $364(11.7)$ & $297(9.5)$ & $0.81(0.70-0.93)$ & 0.004 \\
\hline
\end{tabular}

* $\mathrm{Cl}$ denotes confidence interval, and MI myocardial infarction.

$\dagger \mathrm{PCl}$-related coronary complications included death, $\mathrm{MI}$, or stroke at 48 hours as well as the events listed. $\uparrow$ All cases of catheter-related thrombi were centrally adjudicated.

enoxaparin with respect to the primary composite outcome of death, myocardial infarction, or refractory ischemia at nine days. Analysis of the rates of each component of the composite outcome, including death or myocardial infarction, yielded similar results. When we examined the 30-day outcomes, however, there was a strong trend toward superiority with fondaparinux. Fondaparinux significantly reduced the rate of death as well as the rate of the composite of death, myocardial infarction, and stroke at these times. 
Major bleeding was reduced by about half and minor bleeding by about two thirds with fondaparinux. The prespecified analysis combining efficacy and safety was significantly reduced with fondaparinux. Bleeding increased the long-term risk of death, ${ }^{18}$ and differences in bleeding appeared to account for the reduction in the longterm risk of death with fondaparinux. In addition, there were significantly fewer strokes with fondaparinux than with enoxaparin. Therefore, the net clinical benefit is clearly in favor of fondaparinux. The reduction in bleeding was consistently observed for episodes that were fatal, serious, or minor. The last category included cases in which one unit of blood was transfused or study medications were stopped. Several previous studies have found increased rates of death, stroke, and myocardial infarction among persons who had a bleeding episode. ${ }^{6,18}$ In the context of current treatments for acute coronary syndromes, the rate of major bleeding with enoxaparin is higher than the rate of death, myocardial infarction, or refractory ischemia when each outcome is considered separately. Therefore, although the contemporary practice of using multiple antiplatelet agents, ${ }^{19} \mathrm{a}$ thrombin inhibitor, and an invasive strategy may have substantially reduced ischemic events, it has also increased bleeding.

Fondaparinux is an alternative to enoxaparin because it preserves short-term efficacy but substantially reduces bleeding. This effect translates into lower long-term rates of death, myocardial infarction, and stroke. The reasons for increased bleeding with enoxaparin are unclear but may relate to the intrinsic properties associated with inhibiting thrombin (trials of direct thrombin inhibitors have shown increased bleeding when those agents are compared with unfractionated heparin $)^{20}$; in addition, it is possible that the currently recommended doses of enoxaparin may be too high (although the efficacy of lower doses has not been proven). The rates of bleeding with enoxaparin in OASIS- 5 were lower than those in previous trials. ${ }^{7,21}$ The mechanisms underlying the increased mortality or morbidity associated with bleeding are unclear but may relate to rebound ischemic events due to activation of clotting, cessation of antithrombotic therapies after a bleeding event, or adverse effects of hypotension or transfusions. Given that major bleeding has serious long-term consequences, treatment strategies that reduce the risk of bleeding while maintaining or enhancing the benefits of reduced ischemic events are required. Fondaparinux is an important step toward such a strategy.

The reduced rates of bleeding with fondaparinux were consistently observed in all the subgroups examined. The recent Superior Yield of the New Strategy of Enoxaparin, Revascularization, and Glycoprotein IIb/IIIa Inhibitors (SYNERGY) trial $^{21}$ found a higher rate of bleeding among patients who received additional unfractionated heparin with enoxaparin than among those who received enoxaparin alone. However, this result cannot explain the reduced risk of bleeding associated with fondaparinux in our trial, since less bleeding was observed even among patients who did not receive any unfractionated heparin. The regimen of enoxaparin that we used (with a reduced dose in cases of severe renal impairment) is the standard currently recommended, ${ }^{19}$ and an excess of bleeding with enoxaparin was seen among patients with low or elevated creatinine clearances.

In summary, fondaparinux at a dose of $2.5 \mathrm{mg}$ daily is similar to enoxaparin in the short term in preventing ischemic events among patients with acute coronary syndromes without ST-segment elevation, but it is associated with substantially less bleeding - an effect that translates into lower long-term mortality and morbidity. Therefore, fondaparinux is an attractive option as an anticoagulant in the short-term care of patients with acute coronary syndromes.

Supported by Sanofi-Aventis, Organon, and GlaxoSmithKline.

Dr. Yusuf reports having served as a consultant and having received lecture fees and research grants from Sanofi-Aventis, the manufacturers of enoxaparin, and GlaxoSmithKline, the manufacturers of fondaparinux. Dr. Mehta and Prof. Wallentin report having received lecture fees, consulting fees, and grant support from Sanofi-Aventis and GlaxoSmithKline. Dr. Granger and Prof. Budaj report having received consulting fees, lecture fees, and research grants from Sanofi-Aventis and GlaxoSmithKline. Prof. Peters and Prof. Bassand report having received consulting fees and lecture fees from Sanofi-Aventis and GlaxoSmithKline. Dr. Joyner reports having received grant support from Sanofi-Aventis. Prof. Fox reports having received consulting fees and lecture fees from Sanofi-Aventis and research grant support from both Sanofi-Aventis and GlaxoSmithKline. None of the above investigators are employees of a pharmaceutical company, and none possess stocks or equities in Sanofi-Aventis or GlaxoSmithKline. No other potential conflict of interest relevant to this article was reported.

We are indebted to the patients who agreed to participate in the trial, to Judy Lindeman for secretarial assistance, and to Ton Lensing and Inge Bobbink (of Organon), Roger Cariou and Angele Moryusef (of Sanofi-Aventis), and Steve Okada, Nevine Zariffa, Shiona Laing, and Lawson Macartney (of GlaxoSmithKline) for their support and assistance. 
APPENDIX

The OASIS- 5 committee members and investigators are as follows: Operations committee: S. Yusuf (principal investigator and chair), S.R. Mehta (project director), J.P. Bassand, A. Budaj, ${ }^{\star}$ S. Chrolavicius (project manager), K.A.A. Fox (cochair), C.B. Granger, C. Joyner ${ }^{\star}$ (event adjudication committee chair), R.J.G. Peters, L. Wallentin; Steering committee: A. Avezum, ${ }^{\star}$ W. Boden, E. Cardona, ${ }^{\star}$ L. Ceremuzynski, J. Col, P.J. Commerford, ${ }^{\star}$ R. Diaz, ${ }^{\star}$ D. Faxon, M. Flather, G. Fodor, ${ }^{\star}$ M.-G. Franzosi, C. Granger, D. Halon, D. Hunt, ${ }^{\star}$ N. Karatzas, ${ }^{\star}$ M. Keltai, ${ }^{\star}$ M. Kenda, J.-H. Kim, F. Lanas, ${ }^{\star}$ C.P. Lau, ${ }^{\star}$ B.S. Lewis, J. Morais, ${ }^{\star}$ T. Moccetti, P. Pais, E. Paolasso, ${ }^{\star}$ A. Parkhomenko, ${ }^{\star}$ B. Petrauskiene, ${ }^{\star}$ L. Piegas, ${ }^{\star}$ A. Pipilis, D. Robaayah, M. Ruda, Z. Rumboldt, ${ }^{\star}$ H.-J. Rupprecht, E. Sitkei, ${ }^{\star}$ P.G. Steg, ${ }^{\star}$ E. Swahn, P. Theroux, V. Valentin, ${ }^{\star}$ J. Varigos, J. Weitz, H. White, P. Widimsky, ${ }^{\star}$ D. Xavier, J.R. Zhu, plus members of the operations committee; Adjudication committee: The above-listed persons whose names are indicated by asterisks and S. Ameriso, C. Bonilla, S. Braekken, Y.K. Chan, W. Chen, M. Chenniappan, E. Cohen, Y. Cottin, L. Csiba, A. Czepiel, H. De Raedt, G. Finet, E. Gardinale, E. Gaxiola, A. Gorecki, P. Gregor, O. Happola, M. Heras, D. Himbert, O. Irkin, K. Isaaz, S.S. Iyengar, P. Kalvach, L. Kevers, B. KlosiewiczWasek, M. Laine, D. Leys, E. Lundstrom, I. Lusic, Y. Lutay, A. Maggioni, A. Massaro, B.M. Mayosi, T. Moulin, J. Narendra, U. Naslund, A. Peeters, M. Penicka, A. Perakis, P. Petersen, S. Polic, S. Radhakrishnan, J. Renkin, B. Stockins, R. Sundararajan, K. Thygesen, F. Turazza, E. Van Belle, H. Vik-Mo, and J. Zaborski; Data and safety monitoring board: P. Sleight (chair), J.L. Anderson, D.E. Johnstone, J. Hirsh, D. deMets, D.R. Holmes, Jr.; Project office: B. Meeks (coordinator), R. Afzal and J. Pogue (statisticians), and S. Boccalon, K. Chrysler, B. Cracknell, C. Horsman, T. Hoskin, B. Jedrzejowski, J. Johnson, S. Kotlan, M. Lawrence, M. Smiley, C. Stevens, R. Yallup; Medical help line: S. Connolly, C. Demers, P.J. Devereaux, J. Healey, E. Lonn, P. Magloire, R. McKelvie, C. Morillo, M. Natarajan, M. Rokoss, K. Teo, N. Valettas, J. Velianou; Investigators: Argentina (889 patients) - J.P. Albisu, M. Amuchastegui, F.A. Bello, J.J. Bluguermann, J.O. Bono, A. Caccavo, O.O. Carlevaro, A. Cassettari, C. Cuneo, H.A. Farrás, J. Fuselli, M. Garrido, R. Guerrero, E. Hasbani, M.A. Hominal, A. Hrabar, L. Lobo Marquez, H.L. Luciardi, L. Martínez Riera, E.M. Marzetti, R. Memoli, R. Nordaby, A.D. Orlandini, M. Perez, J.A. Piasentin, H.R. Ramos, A.M. Risolo, J. Sala, O. Salomone, P.O. Schygiel, J. Ubaldini, M. Vico; Australia (523) — J. Amerena, L. Arnolda, G. Aroney, P. Boyd, P. Cahill, D. Chew, J.T. Counsell, D. Cross, J. Edington, D. Fitzpatrick, P. Hicks, J.D. Horowitz, M.C.G. Horrigan, G. New, D. Owensby, M. Schoeman, P. Thompson, G. Tulloch, J. Waites, A. Whelan, R. Ziffer; Austria (184) — K. Huber and N. Jordanova; Belgium (424) - K. Al Shawafi, C. Convens, P. Coussement, A. de Meester, D. El Allaf, L. Janssens, O. Marcovitch, L. Muyldermans, J. Roosen, F. Soeur, J. Van Lierde, M. Vrolix; Brazil (831) - P. Leaes, A.C. Carvalho, E. Costa Schramm, R. D’Aurea Mora, Jr., J. de Castro Amino, O. Dutra, E.R. Fernandes Manenti, C. Gun, J.F. Kerr Saraiva, E. Key Hayashi, A. Lichter, A. Lima Filho, J.A. Marin-Neto, S.P. Minhoto Teixeira, J.A. Miranda Abrantes, L. Moreira Baracioli, J.C. Nicolau, L. Nigro Maia, C. Pederneiras Jaeger, J. Péricles Esteves, A. Rabelo, Jr., R.F. Ramos, G. Reis, P. Rossi, F. Rossi dos Santos, M. Silveira Teixeira, D. Souto Silveira, M.A.B. Teixeira Lemos, A. Timerman, G. Valdir Greque, R. Vaz; Canada (1403) — R. Bhargava, S. Brons, M. Colclough, C. Constance, P. Costi, A. Dacyk, T. Davies, J. Diodati, R. Dupuis, H. Elliott, D.A. Fell, A.Y. Fung, P.J.S. Gladstone, G. Gosselin, F. Grondin, T. Huynh, I. Janzen, T. Kalaparambath, J. Kornder, S. Kouz, R. Kuritzky, S. Labelle-Stimac, M. Lamothe, C. Lauzon, M. LeMay, P. Ma, G.C. MacCallum, A. McCallum, D. Mitchell, M. Montigny, N. Nguyen, M. Pearce, K.J. Pistawka, T. Rebane, M. Roy, M. Senaratne, J. Smith, J. Stimac, M. Traboulsi, S. Vizel, A. Weeks, R. Zadra, R.H. Zimmerman; Chile (65) - M.E. Alcaino, P. Castro; China (341) - J. Chen, J. Chen, J.L. Chen, W. Fan, J. Ge, D. Hu, J. Huang, G. Jingxuan, Y. Ke, H. Ma, Y. Wu, S. Yingxian, B. Yu, W. Zhu; Croatia (312) - M. Bakula, M. Bergovec, A. Lukin, G. Milicevic, M. Padovan, S. Polić, M. Raguz; Czech Republic (1092) - M. Aschermann, J. Belohlavek, P. Bocek, M. Branny, T. Budesinsky, L. Groch, F. Holm, P. Jansky, P. Jelínek, V. Jirka, M. Kaislerová, P. Konecny, L. Lisa, M. Maly, G. Marcinek, M. Oscipovsky, J. Stumar, M. Vácha;. Denmark (77) — T. Nielsen, E. Vigholt; Estonia (127) — P. Laanmets, U. Soopold, J. Voitk; Finland (113) - H. Näveri, M. Niemela, K. Peuhkurinen, P. Tuomainen, A. Ylitalo; France (1005) - A. Py, G. Amat, G. Bessede, J. Boschat, D. Carrie, B. Charbonnier, J.P. Coliet, P. Dambrine, J.L. Dubois-Rande, E. Ferrari, R. Fouche, G. Grollier, O. Jaboureck, R. Ketelers, K. Khalife, F. Leroy, T. Lognone, I. Macquin-Mavier, G. Montalescot, G. Pacouret, J.E. Poulard, J. Puel, M. Richard, F. Schiele; Germany (858) — K.O. Bischoff, M. Buerke, U. Buerke, K. Dominick, H. Drexler, A. Feiler, H. Guelker, G. Haltern, H.A. Katus, V. Klauss, M. Klutmann, O. Koeth, G. Meinhardt, T.M. Muenzel, T. Nitschke, M. Offterdinger, J. Rieber, B. Schieffer, K. Stangl, V. Stangl, J. vom Dahl, B. Witzenbichler, U. Zeymer; Greece (398) - D. Alexopoulos, N. Blassopoulou, A. Christon, I. Fotiadis, S. Foussas, N. Grapsas, N. Moschos, E. Papasteriadis, D. Symeonidis, A. Tyrologos; Hong Kong (52) - W.S. Leung, S.K. Li; Hungary (970) - H. Arabadzisz, J. Csikazs, T. Dancs, Z. Davidovits, I. Edes, E. Farkas, B. Herczeg, S. Janos, A. Janosi, A. Kadar, E. Kis, E. Kristof, G. Lupkovics, L. Mark, A. Nagy, L. Nagy, F. Poor, L. Regos, J. Sebo, J. Tomcsányi, K. Toth; India (522) - A. Bharani, N. Chidambaram, K.K. Haridas, S.S. Iyengar, A. Jain, A. Jain, P.R.K. Jain, T.M. Jaison, P.G. Kerkar, S. Naik, A. Nambiar, J. Narendra, R.B. Panwar, K. Parikh, V.K. Puri, T. Rajesh, M. Ramesh, B. Singh, S. Thanikachalam, R.K. Tongia, S. Varma; Italy (779) - M. Barbiero, G. Bardelli, D. Bernardi, L. Bolognese, L. Capponi, G. De Ferrari, R. Fanelli, L. Frediani, M. Galli, A. Izzo, A. Lombardi, A. Maresta, A. Martinoni, C. Melloni, P. Meneghetti, M. Mennuni, L. Moretti, M. Orlandi, L.G. Pancaldi, S. Petronzelli, G. Piovaccari, A. Salvioni, D. Severini, P. Terrosu, R. Zanini; Latvia (75) - A. Erglis, U. Kalnins, J. Verboenko, I. Zakke; Lithuania (101) - R. Kugiene, R. Zaliunas; Malaysia (114) - A. Bin Othman, K.H. Chee, S.K. Hian; Mexico (142) - A. Castro Gutierrez, A. Cruz Diaz, A. Garcia-Castillo, M.C. Guerrero, C. Lopez Morales, G. Ramos-López; the Netherlands (1012) - S.C. Baldew, D.C.G. Basart, N. Clappers, M.C.G. Daniels, G.J. de Weerd, F.R. den Hartog, I.H.G.M. Hendriks, J.P.R. Herrman, M. Kofflard, K. Krasznai, H.R. Michels, I. Stoel, J.M. ten Berg, V.A.W.N. Umans, G.J. van Beek, M.E.R.M. van Daele, B.J. van den Berg, M.W.J. van Hessen, P.M. van Kalmthout, P. van Rossum, F.W.A. Verheugt, E.P. Viergever, A.J.A.M. Withagen; Poland (2465) — P. Achremczyk, P. Arasimowicz, T. Baranowska, J. Biegayto, M. Bronisz, P. Buszman, A. Czepiel, M. Dalkowski, M. Dluzniewski, J. Gessek, J.H. Goch, A. Gorecki, K. Janik, M. Janion, D. Kawecki, A. Kleinrok, P. Komorowski, W. Krasowski, M. Krauze-Wielicka, S. Malinowski, T. Nowak, P. Nowakowski, M. Ogorek, M. Piepiorka, W. Pluta, E. Puzio, M. Puzniak, J. Rekosz, P. Rybka, D. Sendrowski, T. Siminiak, M. Skura, M. Stopinski, R. Szetemej, M. Szolkiewicz, M. Szpajer, M. Trusz-Gluza, T. Waszyrowski, K. Wita, J. Wodniecki, P. Wojewoda, J. Zambrzycki, Z. Zielinski; Portugal (153) - P. Cardoso, D.M. Carrageta, D. Ferreira, M.V. Gomes, L. Santos; Russia (760) - M. Arkhipov, Y. Belousov, R. Charchoglyan, I.G. Gordeev, N.A. Gratsiansky, Y. Grinshtein, O. Khrustalev, V.A. Kokorin, A. Komarov, V. Kozulin, L.O. Minushkina, E. Panchenko, A. Panov, E.S. Petrik, R.M. Shakhnovich, S.V. Shalaev, T.S. Sukhinina, I.R. Trifonov, D.A. Zateyshchikov; Singapore (68) - B. Chung Hoe Khoo, H.C. Tan, R.S. Tan; Slovakia (174) - V. Hricak, Z. Motovska, P. Poliacik; Slovenia (73) - V. Kanic, D. Kovačič, I. Kranjec, G. Voga; South Africa (196) - J. Bayat, M.R. Essop, F. Maritz, J.D. Marx, M. Ntsekhe, M.P. Pretorius, N. Ranjith, H. Theron; South Korea (277) - I.H. Chae, S.C. Chae, K.H. Choe, N.S. Chung, M.H. Jeong, C.J. Kim, H.S. Kim, W. Kim, C.Y. Rhim, E.K. Shin, G.J. Shin; Spain (645) - M. Alameda, N. Alonso-Orcajo, A. Bethencourt, F. Calvo, J.L. Carpintero Avellaneda, V. Delgado, O. Díaz-Castro, E. Esplugas, R. Faus, A. Fernandez-Ortiz, A. Frutos, P. Goirena, M. Heras, F.C. Iglesias, A.R. Llorian, C. Macaya, X. Mancisidor, R. Melgares, C. Pascual, J.M. Ruiz-Nodar, J.M. Simon; Sweden (782) - S. Agewall, P. Ahlström, M. Ali, L. Andersson, S. Bandh, C. Digerfeldt, H. Ericsson, M. Forsgren, J. Jabro, M. Janzon, H. Joborn, N. Johnston, J.E. Karlsson, L.E. Lars- 
son, C. Linderfalk, I. Lönnberg, T. Mooe, U. Näslund, J. Oldgren, E. Pihl, M. Risenfors, E. Sjölund, I. Söderberg, A. Stjerna, L. Svennberg, P. Wodlin; Switzerland (256) - A. Pagnamenta, M. Pieper, M.G. Rossi, K. Weber; Taiwan (103) — M.C. Peng, J.J. Cheng, F.T. Chiang, C.T. Kuo, C.D. Tseng; Ukraine (634) - I. Andreyeshcheva, G.V. Dzyak, L. Fedtchouk, A. Gontar, O. Karpenko, L. Kononenko, E.A. Koval, I. Kovalsky, I. Kraitz, Y. Lutay, V. Netiazhenko, S. Polyvoda, Y. Prokopenko, I. Prudkiy, L. Rudenko, N. Serediuk, V. Zolotaykina; United Kingdom (301) - J. Adgey, A. Ahsan, M. Brack, A.B. Bridges, J. Burton, I. Findlay, D.S. Fluck, L. Radford, R.H. Robson, R. Senior, I.R. Starkey; United States (759) - J. Alexander, Z. Baber, M. Campbell, R. Caputo, H. Chandna, Y. Chandrashekhar, A. Chu, R.E. DeRaad, B. Druken, A. Goyal, D. Holly, A. Kemp, D. Kotlaba, M.J. Levine, G.P. Miller, T. Nygaard, D.K. Parikh, C. Ramos, E. Rivera, R. Rodriguez, B. Sangani, J.S. Walder. Only investigators from centers that included at least 12 patients are listed here. A complete list appears in the Supplementary Appendix.

REFERENCES

1. Eikelboom JW, Anand SS, Malmberg K, Weitz JI, Ginsberg JS, Yusuf S. Unfractionated heparin and low-molecular-weight heparin in acute coronary syndrome without ST elevation: a meta-analysis. Lancet 2000;355:1936-42. [Erratum, Lancet 2000; 356:600.]

2. Antithrombotic Trialists' Collaboration Collaborative meta-analysis of randomised trials of antiplatelet therapy for prevention of death, myocardial infarction, and stroke in high risk patients. BMJ 2002;324:71-86. [Erratum, BMJ 2002;324:141.]

3. Yusuf S, Zhao F, Mehta SR, Chrolavicius $S$, Tognoni G, Fox KA. Effects of clopidogrel in addition to aspirin in patients with acute coronary syndromes without ST-segment elevation. N Engl J Med 2001 345:494-502. [Errata, N Engl J Med 2001; 345:1506, 1716.]

4. Boersma E, Harrington RA, Moliterno DJ, et al. Platelet glycoprotein IIb/III inhibitors in acute coronary syndromes a meta-analysis of all major randomised clinical trials. Lancet 2002;359:189-98. [Erratum, Lancet 2002;359:2120.]

5. Mehta SR, Cannon CP, Fox KA, et al Routine vs selective invasive strategies in patients with acute coronary syndromes: a collaborative meta-analysis of random ized trials. JAMA 2005;293:2908-17.

6. de Araújo Gonçalves P, Ferreira J, Aguiar C, Seabra-Gomes R. TIMI, PURSUIT, and GRACE risk scores: sustained prog nostic value and interaction with revascularization in NSTE-ACS. Eur Heart J 2005 26:865-72.

7. Petersen JL, Mahaffey KW, Hasselblad V, et al. Efficacy and bleeding complications among patients randomized to enoxaparin or unfractionated heparin for antithrombin therapy in non-ST-segment elevation acute coronary syndromes: a sys tematic overview. JAMA 2004;292:89-96.

8. Weitz JI, Hirsh J. New anticoagulant drugs. Chest 2001;119:Suppl:95S-107S.
9. Turpie AGG, Bauer KA, Eriksson BI Lassen MR. Fondaparinux vs enoxaparin for the prevention of venous thromboembolism in major orthopaedic surgery: a metaanalysis of 4 randomized double-blind studies. Arch Intern Med 2002;162:183340.

10. Buller HR, Davidson BL, Decousus H et al. Fondaparinux or enoxaparin for the initial treatment of symptomatic deep venous thrombosis: a randomized trial. Ann Intern Med 2004;140:867-73.

11. The Matisse Investigators. Subcutaneous fondaparinux versus intravenous unfractionated heparin in the initial treatment of pulmonary embolism. N Engl J Med 2003;349:1695-702. [Erratum, N Eng J Med 2004;350:423.

12. Simoons ML, Bobbink IWG, Boland J, et al. A dose-finding study of fondaparinux in patients with non-ST-segment elevation acute coronary syndromes: the Pentasaccharide in Unstable Angina (PENTUA) Study. J Am Coll Cardiol 2004; 43:2183-90.

13. Coussement PK, Bassand JP, Convens $\mathrm{C}$, et al. A synthetic factor-Xa inhibito (ORG31540/SR9017A) as an adjunct to fibrinolysis in acute myocardial infarction the PENTALYSE study. Eur Heart J 2001 22:1716-24.

14. Mehta SR, Steg PG, Granger CB, et al Randomized, blinded trial comparing fondaparinux with unfractionated heparin in patients undergoing contemporary percutaneous coronary intervention: Arixtra Study in Percutaneous Coronary Intervention: a Randomized Evaluation (ASPIRE) Pilot Trial. Circulation 2005;111:1390-7. 15. MICHELANGELO OASIS 5 Steering Committee. Design and rationale of the MICHELANGELO Organization to Assess Strategies in Acute Ischemic Syndromes (OASIS)-5 trial program evaluating fondaparinux, a synthetic factor $\mathrm{Xa}$ inhibitor, in patients with non-ST-segment elevation acute coronary syndromes. Am Heart 2005;150:1107.

16. Wiens BL. Choosing an equivalent limit for noninferiority or equivalence studies. Control Clin Trials 2002;23:2-14. [Erratum, Control Clin Trials 2002;23:774.]

17. Cannon CP, Battler A, Brindis RG, et al. American College of Cardiology key data elements and definitions for measuring the clinical management and outcomes of patients with acute coronary syndromes: a report of the American College of Cardiology Task Force on Clinical Data Standards (Acute Coronary Syndromes Writing Committee). J Am Coll Cardiol 2001;38: 2114-30.

18. Rao SV, Jollis JG, Harrington RA, et al. Relationship of blood transfusion and clinical outcomes in patients with acute coronary syndromes. JAMA 2004;292: 1555-62.

19. Braunwald E, Antman EM, Beasley JW, et al. ACC/AHA 2002 guideline update for the management of patients with unstable angina and non-ST-segment elevation myocardial infarction — summary article: a report of the American College of Cardiology/American Heart Association Task Force on Practice Guidelines (Committee on the Management of Patients With Unstable Angina). J Am Coll Cardiol 2002;40:1366-74

20. Direct Thrombin Inhibitor Trialists' Collaborative Group. Direct thrombin inhibitors in acute coronary syndromes: principal results of a meta-analysis based on individual patients' data. Lancet 2002; 359:294-302.

21. Ferguson JJ, Califf RM, Antman EM, et al. Enoxaparin vs unfractionated heparin in high-risk patients with non-ST-segment elevation acute coronary syndromes managed with an intended early invasive strategy: primary results of the SYNERGY randomized trial. JAMA 2004;292:45-54. Copyright (c) 2006 Massachusetts Medical Society. 